\title{
The relation of flow-mediated vasodilatation and diastolic function in uncomplicated Type 2 diabetic patients ${ }^{*}$
}

\section{J. Charvat", J. Chlumsky, P. Svab, M. Peckova}

Department of Medicine, 2nd Medical Faculty, Charles University and Faculty Hospital Motol, Prague, Czech Republic;

${ }^{\#}$ Corresponding Author: jiri.charvat@1fmotol.cuni.cz

Received 8 February 2013; revised 9 March 2013; accepted 17 March 2013

Copyright (C) 2013 J. Charvat et al. This is an open access article distributed under the Creative Commons Attribution License, which permits unrestricted use, distribution, and reproduction in any medium, provided the original work is properly cited.

\begin{abstract}
Objectives: To evaluate the association of diastolic function of the left ventricle with flow- mediated dilatation (FMD) in uncomplicated Type 2 diabetes mellitus patients. Methods: Eighty-two uncomplicated Type 2 diabetic patients were examined by pulse and tissue Doppler echocardiography and FMD of brachial artery. The patients were divided into $\mathbf{2}$ groups according to the size of the left ventricular relaxation parameter-E'. Results: The average age of the patients was 61 \pm 6 years. FMD was $5.0 \pm 1.8 \%$ in 41 patients with E' from 3 to $7.4 \mathrm{~cm} / \mathrm{s}$ (mean $6 \mathrm{~cm} / \mathrm{s}$ ) comparing to $5.1 \pm 1.9 \%(p=0.96)$ in 41 patients with $E^{\prime}$ from 7.5 to $10.9 \mathrm{~cm} / \mathrm{s}$ (mean $8.9 \mathrm{~cm} / \mathrm{s}$ ). E/E' was $11.2 \pm$ 2.3 in the group with lower E' and $9.1 \pm 1.6$ in the group with higher E' $(p<0.001)$. Linear negative correlation was found between E/E' and FMD for the patients with $E^{\prime}$ from 3 to $7.4 \mathrm{~cm} / \mathrm{s}\left(R^{2}=0.131\right.$; $p=0.025$ ) but not for the group of patients with the higher E'. The significant association between FMD and E/E' was confirmed by multivariate analysis $\left(\left(R^{c}\right)^{2}=0.233 ; p<0.05\right)$. Conclusion: FMD has no impact on the left ventricular relaxation. However FMD is negatively associated with E/E' in Type 2 diabetic patients who have low E' as a sign of an impaired early relaxation.
\end{abstract}

Keywords: Flow-Mediated Vasodilatation; Tissue and Pulse Doppler Echocardiography; Type 2 Diabetes Mellitus; Diastolic Function; Left Ventricular Relaxation

${ }^{*}$ Conflict of interest: None declared.

\section{INTRODUCTION}

Endothelial dysfunction is independently associated with diastolic dysfunction in humans [1]. Flow-mediated dilatation (FMD) of brachial artery is recognized parameter of endothelial function and is associated with cardiovascular prognosis [2,3]. It is significantly more deteriorated in patients with Type 2 diabetes mellitus in comparison to nondiabetic subjects [4]. Diastolic heart failure and diastolic dysfunction are also frequent in patients with Type 2 diabetes mellitus $[5,6]$.

However there are only limited data about the association of flow-mediated vasodilatation of brachial artery with diastolic function in patients suffering from Type 2 diabetes mellitus [7].

The aim of our study was to evaluate if FMD is associated with an early stage of diastolic dysfunction characterized by the incipient impairment of the left ventricular relaxation in patients with uncomplicated Type 2 diabetes mellitus without any previous cardiovascular accident, microalbuminuria and systolic dysfunction.

In order to answer this question the relation between FMD of brachial artery and echocardiography parameters of diastolic function examined by pulse and tissue Doppler echocardiography was evaluated.

\section{SUBJECTS AND METHODS}

Patients with Type 2 diabetes mellitus were examined at the Department of Medicine, University Hospital Prague Motol, Czech Republic. The diagnosis of Type 2 diabetes mellitus was based on the following: clinical findings, fasting blood glucose, C-peptide measurement and a negative finding for anti-beta-cell antibodies at least 1 year prior to enrolment in the study. The patients were only included in the study if their casual blood pressure was well controlled regardless of treatment for arterial hypertension-equal or below 135/85. Patients 
with a history of cardiovascular or other heart diseases, presence of regional LV kinetic abnormalities or a global LV ejection fraction $<55 \%$, a history of severe GFR impairment $\left(<0.5 \mathrm{ml} / \mathrm{s} / 1.73 \mathrm{~m}^{2}\right)$ and/or microalbuminuria, or a prognosis of a life-limiting disease were excluded. The patients were divided into 2 equal groups according to size of E'-parameter of an early left ventricular relaxation.

The study was approved by the Ethics Committee of the University Hospital Motol and undertaken in accordance with the Declaration of Helsinki.

Transthoracic echocardiography, including pulse Doppler and tissue Doppler imaging (TDI) were performed using a Philips Sonos ${ }^{\circledR} 7500$ cardiac ultrasound unit (Philips Healthcare, Andover, MA, USA).

Interventricular septal thickness (IVSd), posterior wall thickness (PWd), LV diastolic diameter (LVDd), LV systolic diameter (LVDs), and left atrial diameter were determined. Left ventricular mass (LVM) was calculated by the following equation: LVM $(\mathrm{g})=1.04 \times[(\mathrm{IVSd}+$ LVDd + PWd $)^{3}-$ LVDd $\left.^{3}\right]-13.6$. Left ventricular mass index (LVMI) was determined as LVM/body surface area. Ejection fraction of the left ventricle was evaluated according to Teicholz equation [8].

Mitral inflow velocity was traced and the following variables of diastolic function were measured and evaluated: peak velocities of early (E) and late (A) transmitral flow, the ratio $\mathrm{E} / \mathrm{A}$, and deceleration time (DT). The peak velocities of early (E') and late (A') diastolic mitral annular motion (average of septal and lateral values) were determined from TDI recordings, and mitral $\mathrm{E} / \mathrm{E}$ ' and E'/A' ratios were calculated. In our laboratory, approximately 4 weeks apart the mean intra-observer difference was $3.6 \%$ and inter-observer difference $4.6 \%$.

Endothelial function was evaluated by measuring the FMD of the brachial artery using a standardized protocol. FMD of the brachial artery was examined with scanner CC-15M71-MA (Toshiba, Otawara, Japan).

Subjects were required to be fasting and not use any tobacco-containing products for 8 hours before the study. Subjects were placed in a supine position in a temperature-controlled room for 10 min before imaging. A blood pressure cuff was placed on the widest part of the proximal right forearm. Using a $10-\mathrm{MHz}$ linear array vascular ultrasound transducer was located above the elbow and scanned in longitudinal sections. After recording baseline B-mode ultrasound images of the brachial artery, the cuff was inflated to $250 \mathrm{~mm} \mathrm{Hg}$ for $5 \mathrm{~min}$ to induce reactive hyperaemia. Brachial artery images were obtained 60 and 90 seconds after deflation. Studies were recorded digitally. The primary outcome variable was the maximum FMD (in \%), the largest percentage of change in the brachial artery diameter after reactive hyperaemia relative to the baseline diameter. The absolute maximum
FMD (in $\mathrm{cm}$ ), the absolute difference in brachial artery size after reactive hyperaemia compared with baseline, also was reported.

In our laboratory, approximately 4 weeks apart had an interscan FMD difference of only $0.36 \%$ and the median inter-reader variability was from $-0.24 \%$ to $+0.12 \%$.

Biochemical examination of blood samples included glycosylated haemoglobin $\left(\mathrm{HbA}_{1 \mathrm{c}}\right)$, lipid analysis and creatinine. $\mathrm{HbA}_{1 \mathrm{c}}$ was measured using high-performance liquid chromatography and a spectrophotometer detection system (Tosoh G8 analyser; Tosoh Corporation, Tokyo, Japan) with a normal range of 2.8\% - 4.5\% (7 - 26 $\mathrm{mmol} / \mathrm{mol}$ ) according to the International Federation of Clinical Chemistry and Laboratory Medicine. Low-density lipoprotein (LDL) and high-density lipoprotein (HDL) cholesterol were measured using a direct enzymatic method with catalase; triglycerides were measured using the Fossati enzymatic method and serum creatinine (SCr) was measured using an enzymatic method; all of which were performed by an ADVIA ${ }^{\circledR} 1800$ Clinical Chemistry System (Siemens Medical Solutions, Tarrytown, NY, USA). Glomerular filtration (eGFR) was estimated using the abbreviated Modification of Diet in Renal Disease equation: $2.92 \times(\mathrm{SCr} \times 0.011312)^{-1.154} \times$ age $^{-0.203}$ (if female $\times 0.742$ ).

\section{STATISTICAL EVALUATION}

Continuous variables are given as mean $\pm \mathrm{SD}$. Between-group comparisons of continuous parameters were performed by Mann-Whitney test. The $x^{2}$-test was used to compare categorical variables. Relationships between continuous variables were assessed using linear regression analysis. In order to detect the independent predictors of the parameters of diastolic function (E/A, E', E/E' and $\left.E^{\prime} / A^{\prime}\right)$ multivariate regression analysis using the method of orthogonal projections to latent structure was evaluated. The following parameters were included into multivariate analysis: age, gender, BMI, history of hypertension, $\mathrm{HbA}_{1 \mathrm{c}}$, LDL and HDL cholesterol, systolic and diastolic BP, eGFR, LVMI and FMD. A p-value < 0.05 was considered to be statistically significant. The value $\left(R^{c}\right)^{2}$ expresses the percentage variation of the matrix of the dependent variable explained by the independent variables. Data were analysed using the StatGraphics Centurion Data Analysis and Statistical Software, version XV (Statpoint Technologies Inc., Warrenton, VA, USA).

\section{RESULTS}

The baseline characteristics of 82 patients with Type 2 diabetes mellitus are presented in $1^{\text {st }}$ column of Table 1 and their echocardiography parameters are shown in the $1^{\text {st }}$ column of Table 2 . 
Table 1. Demographic and clinical characteristics of all of the patients with Type 2 diabetes that participated in the study $(\mathrm{n}=82)$ and two groups stratified according to their peak velocity of early diastolic mitral annular motion $\left(\mathrm{E}^{\prime}\right.$ in $\left.\mathrm{cm} / \mathrm{s}\right)$.

\begin{tabular}{|c|c|c|c|c|}
\hline Parameter & Entire cohort & $E^{\prime}(3-7.4)$ & $E^{\prime}(7.5-10.9)$ & $\mathrm{p}$ \\
\hline & $\mathrm{n}=82$ & $\mathrm{n}=41$ & $\mathrm{n}=41$ & \\
\hline Age (years) & $61 \pm 6$ & $62 \pm 6$ & $61 \pm 7$ & NS \\
\hline Gender (number of female/\%) & $28(34 \%)$ & $14(34 \%)$ & $14(34 \%)$ & NS \\
\hline $\operatorname{BMI}\left(\mathrm{kg} / \mathrm{m}^{2}\right)$ & $31 \pm 3.7$ & $30.7 \pm 3.5$ & $31.2 \pm 3.9$ & NS \\
\hline Diabetes duration (years) & $11.2 \pm 7.6$ & $13.4 \pm 8.1$ & $9.0 \pm 6.5$ & 0.007 \\
\hline $\mathrm{HbA}_{1 \mathrm{c}}(\%)$ & $6.0 \pm 1.6$ & $6.4 \pm 1.4$ & $5.6 \pm 1.7$ & 0.023 \\
\hline C-peptide (nmol/l) & $1.26 \pm 0.53$ & $1.33 \pm 0.51$ & $1.18 \pm 0.54$ & NS \\
\hline \multicolumn{5}{|l|}{ Diabetes treatment } \\
\hline Diet only (number/\%) & $5(6.1 \%)$ & $1(2.4 \%)$ & $4(9.7 \%)$ & NS \\
\hline Oral agents (number/\%) & $61(74.4 \%)$ & $27(65.6 \%)$ & $34(82.9 \%)$ & NS \\
\hline Insulin (number/\%) & $4(4.9 \%)$ & $2(4.9 \%)$ & $2(4.9 \%)$ & NS \\
\hline Insulin and oral agents (number/\%) & $12(14.6 \%)$ & $8(19.5 \%)$ & $4((9.8 \%)$ & NS \\
\hline LDL cholesterol (mmol/l) & $2.8 \pm 0.9$ & $2.8 \pm 1.0$ & $2.9 \pm 0.8$ & NS \\
\hline HDL cholesterol (mmol/l) & $1.2 \pm 0.3$ & $1.1 \pm 0.3$ & $1.2 \pm 0.3$ & NS \\
\hline Triacylglycerols (mmol/l) & $2.0 \pm 0.9$ & $2.2 \pm 0.9$ & $1.9 \pm 0.8$ & NS \\
\hline Hypolipidemic treatment & $62(75.6 \%)$ & $32(78 \%)$ & $30(73.2 \%)$ & NS \\
\hline Statins (number/\%) & $52(63.4 \%)$ & $27(65.9 \%)$ & $25(61 \%)$ & NS \\
\hline Fibrates (number/\%) & $11(13.4 \%)$ & $6(14.6 \%)$ & $5(12.2 \%)$ & NS \\
\hline Systolic BP (mmHg) & $133 \pm 8$ & $133 \pm 9$ & $132 \pm 8$ & NS \\
\hline Diastolic BP (mmHg) & $82 \pm 6$ & $83 \pm 6$ & $82 \pm 7$ & NS \\
\hline Treated hypertension (number/\%) & $66(80.5 \%)$ & $33(83 \%)$ & $33(83 \%)$ & NS \\
\hline ACE inhibitors, sartans (number/\%) & $56(68.3 \%)$ & $30(73.2 \%)$ & $26(63.4 \%)$ & NS \\
\hline Beta blockers (number/\%) & $28(34.1 \%)$ & $16(39 \%)$ & $12(29.3 \%)$ & NS \\
\hline Calcium antagonists (number/\%) & $22(26.8 \%)$ & $10(24.4 \%)$ & $12(29.3 \%)$ & NS \\
\hline Diuretics (number/\%) & $30(36.6 \%)$ & $16(39 \%)$ & $14(34.1 \%)$ & NS \\
\hline Other hypotensives (number/\%) & $9(11 \%)$ & $6(14.6 \%)$ & $3(7.3 \%)$ & NS \\
\hline Serum creatinine (umol/1) & $85.9 \pm 19.2$ & $89.5 \pm 20.8$ & $89.5 \pm 17.7$ & NS \\
\hline eGFR $\left(\mathrm{ml} / \mathrm{s} / 1.73 \mathrm{~m}^{2}\right)$ & $1.2 \pm 0.3$ & $1.2 \pm 0.3$ & $1.2 \pm 0.4$ & NS \\
\hline
\end{tabular}

Data are presented as mean \pm SD (range) or n (\%). The difference between subgroups E' $<7.5 \mathrm{~cm} / \mathrm{s}$ and E' $\geq 7.5 \mathrm{~cm} / \mathrm{s}$ was analysed by Mann-Whitney test for continuous data and by $x^{2}$-test for categorical data. NS, not statistically significant $(P>0.05) ; \mathrm{HbA}_{1 \mathrm{c}}$, glycosylated haemoglobin; IFCC, International Federation of Clinical Chemistry and Laboratory Medicine; LDL, low-density lipoprotein; HDL, high-density lipoprotein; eGFR, estimated glomerular filtration rate; MDRD, modification of diet in renal disease; BP, blood pressure; BMI, body mass index.

The patients were divided into 2 groups depending on the size of E'. Forty-one patients with E' from 3 to 7.4 $\mathrm{cm} / \mathrm{s}$ (mean $6 \mathrm{~cm} / \mathrm{s})$ form the $1^{\text {st }}$ group while the patients with E' from 7.5 to $10.9 \mathrm{~cm} / \mathrm{s}$ (mean $8.9 \mathrm{~cm} / \mathrm{s}$ ) were included into another one. The difference of $\mathrm{E}^{\prime}$ between groups was highly significant $(\mathrm{p}<0.001)$. The comparison of baseline characteristics of both groups of patients are summarised in $2^{\text {nd }}$ and $3^{\text {rd }}$ columns of Table 1 and echocardiography parameters in $2^{\text {nd }}$ and $3^{\text {rd }}$ columns of Table 2. 
Table 2. Echocardiography characteristics of all of the patients with Type 2 diabetes that participated in the study $(n=82)$ and two groups stratified according to their peak velocity of early diastolic mitral annular motion (E' in $\mathrm{cm} / \mathrm{s})$.

\begin{tabular}{|c|c|c|c|c|}
\hline Parameter & Entire cohort & $E^{\prime}(3-7.4)$ & $E^{\prime}(7.5-10.9)$ & $\mathrm{p}$ \\
\hline & $\mathrm{n}=82$ & $\mathrm{n}=41$ & $\mathrm{n}=41$ & \\
\hline E/A (ratio) & $0.97 \pm 0.28$ & $0.89 \pm 0.28$ & $1.05 \pm 0.26$ & 0.006 \\
\hline $\mathrm{E}^{\prime}(\mathrm{cm} / \mathrm{s})$ & $7.5 \pm 1.7$ & $6.0 \pm 1.0$ & $8.9 \pm 0.9$ & $<0.001$ \\
\hline E/E' (ratio) & $10.2 \pm 2.2$ & $11.2 \pm 2.3$ & $9.1 \pm 1.6$ & $<0.001$ \\
\hline E'/A' (ratio) & $0.70 \pm 0.19$ & $0.69 \pm 0.19$ & $0.81 \pm 0.17$ & $<0.001$ \\
\hline $\mathrm{DT}(\mathrm{cm})$ & $228 \pm 46$ & $231 \pm 47$ & $225 \pm 44$ & NS \\
\hline IVST (mm) & $11.7 \pm 0.7$ & $11.8 \pm 0.7$ & $11.7 \pm 0.7$ & NS \\
\hline PWT (mm) & $11.9 \pm 0.8$ & $11.8 \pm 0.7$ & $11.9 \pm 0.8$ & NS \\
\hline LVDd (mm) & $46.0 \pm 4.1$ & $45.6 \pm 4.5$ & $46.4 \pm 3.7$ & NS \\
\hline LVDs (mm) & $27.7 \pm 2.7$ & $27.1 \pm 2.9$ & $27.7 \pm 2.4$ & NS \\
\hline LAD (mm) & $37.8 \pm 2.9$ & $37.9 \pm 2.8$ & $37.6 \pm 2.9$ & NS \\
\hline $\mathrm{LAD} / \mathrm{m}^{2}(\mathrm{~mm})$ & $18.3 \pm 2.0$ & $18.5 \pm 2.1$ & $18.0 \pm 1.9$ & NS \\
\hline FS $(\%)$ & $40.2 \pm 16.0$ & $40.2 \pm 1.6$ & $40.0 \pm 1.4$ & NS \\
\hline LVEF (\%) & $61.0 \pm 3.2$ & $60.8 \pm 3.3$ & $61.2 \pm 3.3$ & NS \\
\hline LVM (g) & $274 \pm 44$ & $233 \pm 47$ & $242 \pm 41$ & NS \\
\hline LVMI (g/m²) & $114 \pm 18$ & $113 \pm 20$ & $115 \pm 16$ & NS \\
\hline
\end{tabular}

Data are presented as mean $\pm \mathrm{SD}$ (range). The difference between subgroups $\mathrm{E}^{\prime}<7.5 \mathrm{~cm} / \mathrm{s}$ and E' $\geq 7.5 \mathrm{~cm} / \mathrm{s}$ was analysed by Mann/Whitney test NS, not statistically significant $(\mathrm{P}>0.05)$; E, peak velocity of early transmitral flow; A, peak velocity of late transmitral flow; A', peak velocity of late diastolic mitral annular motion; DT, deceleration time of parameter E; IVST, interventricular septal thickness; PWT, posterior wall thickness; LVDd, left ventricular diastolic diameter; LVDs, left ventricular systolic diameter; LAD, left atrial diameter; FS, fractional shortening; LVEF, left ventricular ejection fraction; LVM, left ventricular mass; LVMI, left ventricular mass index.

FMD of brachial artery was $5.0 \pm 1.8$ in the group with E' between 3 and $7.4 \mathrm{~cm} / \mathrm{sec}$ and $5.1 \pm 1.9 \%$ (N.S) in 41 patients with E' from 7.5 to $10.9 \mathrm{~cm} / \mathrm{s}, \mathrm{p}=0.96$.

The mean diameter of brachial artery before ischaemia in the group of patients with low E' was $0.44 \pm 0.05 \mathrm{~cm}$ comparing to $0.44 \pm 0.06$ with high $E^{\prime}(p=0.98)$ and after ischaemia in the group of patients with low E' was $0.46 \pm 0.05 \mathrm{~cm}$ comparing to $0.46 \pm 0.06 \mathrm{~cm}$ with high $\mathrm{E}^{\prime}$ $(\mathrm{p}=0.96)$

The linear correlations of E', E/A, E'/A' and E/E' with FMD were not significant when evaluating all 82 subjects.

The range of E/E' was 6 to 15 in patients with low E' and 6 to 12 in the group with high E'.

The linear correlation between E/E' and FMD was negatively significant in the group of the patients with $\mathrm{E}$ ' between 3 and $7.4 \mathrm{~cm} / \mathrm{sec}\left(\mathrm{R}^{2}=0.131 ; \mathrm{p}=0.025\right.$; Figure 1) but not in the group with $E^{\prime}$ between 7.5 and 10.9 $\mathrm{cm} / \mathrm{sec}$. No significant correlation was detected between another parameters of diastolic function-E', E/A, E'/A' with FMD in the groups of diabetic patients with the low or high E'.

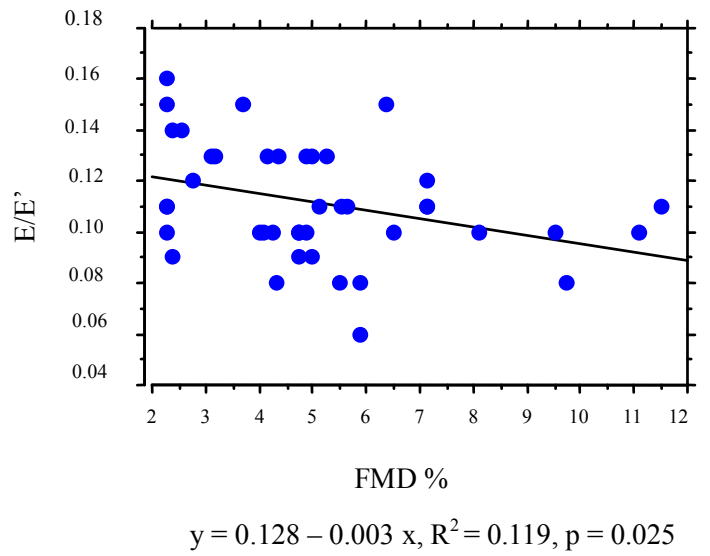

Figure 1. Bivariate regression plot for $\mathrm{E} / \mathrm{E}$ ' and FMD in the group of patients with E' from 3 to $7.4 \mathrm{~cm} / \mathrm{s}$.

The result of multivariate analysis confirmed the significant association of FMD with E/E' (Table 3).

\section{DISCUSSION}

Diastolic dysfunction in Type 2 diabetic patients is 
Table 3. Multivariate analysis.

\begin{tabular}{|c|c|c|c|}
\hline & & $\left(R^{c}\right)^{2}$ & $\mathrm{p}$ \\
\hline \multicolumn{4}{|l|}{$\mathrm{E}^{\prime}$} \\
\hline & $\mathrm{HbA}_{1 \mathrm{c}}$ & 0.579 & $<0.01$ \\
\hline & Duration of diabetes & 0.217 & $<0.05$ \\
\hline \multicolumn{4}{|c|}{$\mathrm{E} / \mathrm{E}^{\prime}$} \\
\hline & Treatment for hypertension & 0.150 & $<0.05$ \\
\hline & FMD of brachial artery & 0.233 & $<0.05$ \\
\hline & eGFR & 0.130 & $<0.05$ \\
\hline \multicolumn{4}{|c|}{$\mathrm{E} / \mathrm{A}$} \\
\hline & Age & 0.661 & $<0.01$ \\
\hline \multicolumn{4}{|c|}{$E^{\prime} / A^{\prime}$} \\
\hline & Age & 0.076 & $<0.05$ \\
\hline & $\mathrm{HbA}_{1 \mathrm{c}}$ & 0.515 & $<0.01$ \\
\hline & Duration of diabetes & 0.217 & $<0.05$ \\
\hline
\end{tabular}

The value $\left(\mathrm{R}^{\mathrm{c}}\right)$ expresses the percent of variation of the matrix of the dependent variable explained by the independent variables; E', early peak diastolic annular velocity of mitral valve; E/E' ratio of early peak transmitral flow velocity to early peak diastolic annular velocity of mitral valve; E'/A', ratio of early to late peak diastolic annular velocity of mitral valve; E/A, ratio of early to late peak diastolic transmitral flow velocities; $\mathrm{HbA}_{1 \mathrm{c}}$, glycosylated haemoglobin; FMD, flow-mediated vasodilatation; eGFR, estimated glomerular filtration rate.

associated with the presence of hypertension and coronary artery disease $[9,10]$. In order to minimize the impact of these factors on parameters of diastolic function the patients with blood pressure exceeding $135 / 85 \mathrm{~mm}$ $\mathrm{Hg}$, history of the previous cardiovascular disease, abnormal ECG, presence of the left ventricular systolic dysfunction on echocardiography examination and microalbuminuria were excluded from entering to this study.

No significant linear correlation between parameters of diastolic function (E/A, E', E'/A' and E/E') and FMD in all 82 patients may be interpreted that in uncomplicated Type 2 diabetic patients there is no relationships between the incipient stage of diastolic dysfunction and flow-mediated vasodilatation.

However the impairment of left ventricular relaxation may be found often in diabetic patients without any clinical cardiovascular complications. Tissue Doppler parameter $\mathrm{E}^{\prime}$ is described as a marker of an early left ventricular relaxation relatively independent of haemodynamic changes [11-13]. The lower is $E^{\prime}$ the higher is probability of abnormal left ventricular relaxation as a marker of the incipient stage of the left ventricular dysfunction [12].

Cut-off point of E' for relaxation impairment depends on age. In patients between 50 and 70 years who were included into our study the mean value of E' in healthy persons is $7.5 \mathrm{~cm} / \mathrm{s}$ [14]. It was reason why the patients with E' below $7.5 \mathrm{~cm} / \mathrm{s}$ (mean $6 \mathrm{~cm} / \mathrm{s}$, range $3-7.4 \mathrm{~cm} / \mathrm{s}$ ) formed one group with high probability of the left ventricular relaxation impairment. The group of patients with normal left ventricular relaxation had E' $7.5 \mathrm{~cm} / \mathrm{s}$ and more (mean $8.5 \mathrm{~cm} / \mathrm{s}$, range $7.5-10.9 \mathrm{~cm} / \mathrm{s}$ ).

There was no significant difference in age, gender, BMI, the presence of hypertension, systolic and diastolic blood pressure, application of treatment for hypertension, lipid abnormalities and diabetes itself, index of mass of the left ventricle and FMD of brachial artery between the diabetic patients according to the size of E'. The patients with E' from 3 to $7.4 \mathrm{~cm} / \mathrm{s}$ have the worse diabetic control $\left(\mathrm{HbA}_{1 \mathrm{c}}\right)$ and longer duration of Type 2 diabetes. These findings are in agreement with some previous studies [15-17].

The parameter E/E' correlates with the left ventricular end-diastolic pressure measured invasively $[11,12]$. Its value rises when the left ventricular relaxation is impaired and so it is also considered as a marker of diastolic function. However it may be changed significantly also by haemodynamic changes [11,12].

FMD in our patients significantly correlated with E/E' only in the group of patients who presented low E'. This finding may be interpreted that improvement of flowmediated vasodilatation leads to decrease of the left ventricular end-diastolic pressure in patients with the left ventricular relaxation impairment.

The presence of no significant difference of FMD between the patients with the low and high E' means that the change of FMD does not lead to change of an early diastolic relaxation in uncomplicated Type 2 diabetic patients. However the impairment of an early diastolic relaxation triggers the relation that between another parameter of diastolic function E/E' and flow-mediated dilatation.

Limitation of our study is mainly in assessment of cutoff point of E' between normal and pathological LV early diastolic relaxation. Most likely cut-off point should be lower than $7.5 \mathrm{~cm} / \mathrm{s}$ because if it was decreased (e.g. 6.5 $\mathrm{cm} / \mathrm{s}$ ) the correlation between E/E' and FMD has become even more significant.

The relationship between endothelial function and an early stage of diastolic dysfunction is also supported by correlation of E/E' with plasma adrenomedullin in Type 2 diabetic patients with low E' [18].

\section{CONCLUSIONS}

The association between E/E' and FMD of brachial artery found in patients with E' from 3 to $7.4 \mathrm{~cm} / \mathrm{s}$ supports the conclusion that the association of flow-mediated vasodilatation and diastolic function in uncompli- 
cated Type 2 diabetic patients is present from an early stage of the left ventricular relaxation impairment.

By this way the improvement of flow-mediated vasodilatation (endothelial function) may have positive effect on haemodynamic situation already in uncomplicated Type 2 diabetic patients.

\section{REFERENCES}

[1] Elesber, A.A., Redfield, M.M., Rihal, C.S., Prasad, A., Lavi, S., Lennon, R., et al. (2001) Coronary endothelial dysfunction and hyperlipidemia are independently associated with diastolic dysfunction in humans. American Heart Journal, 153, 1081-1087. doi:10.1016/j.ahj.2007.03.007

[2] Arrebola-Moreno, A.L., Lacluastra, M. and Kaski, J.C. (2012) Noninvasive assessment of endothelial function in clinical practice. Revista Española de Cardiología, 65, 80-90. doi:10.1016/j.recesp.2011.09.012

[3] Lloyd-Jones, D.M. and Bloch, K.D. (1996) The vascular biology of nitric oxide and its role in atherogenesis. Annual Review of Medicine, 47, 365-375. doi:10.1146/annurev.med.47.1.365

[4] Henry, R.M.A., Fereira, I., Kostense, P.J., Dekker, J.M., Nijpels, G., Heine, R.J. et al. (2004) Type 2 diabetes is associated with impaired endothelium-dependent, flow mediated dilatation, but impaired glucose metabolism is not. The Hoorn Study. Atherosclerosis, 174, 49-56. doi:10.1016/j.atherosclerosis.2004.01.002

[5] Von Bibra H. and St John Sutton, M. (2010) Diastolic dysfunction in diabetes and metabolic syndrome: Promising potential for diagnosis and prognosis. Diabetologia, 53, 1033-1045. doi:10.1007/s00125-010-1682-3

[6] Tsujino, T., Kawasaki, D. and Masayama, T. (2006) Left ventricular diastolic dysfunction in diabetic patients: pathophysiology and therapeutic implications. American Journal of Cardiovascular Drugs, 6, 219-230. doi:10.2165/00129784-200606040-00002

[7] Baykan, M., Erdogan, T., Erem, C., Hacihasanoglu, A., Gedikli, O., Kucukosmanoglu, M. et al. (2006) The relationship between flow-mediated dilatation and left ventricular function in type 2 diabetic patients with microalbuminuria. Endocrine, 30, 197-202. doi:10.1385/ENDO:30:2:197

[8] Teicholz, E., Kreulen, T., Herman, M.V. and Gorlin, R. (1976) Problems in echocardiographic volume determinations: echocardiographic-angiographic correlations in the presence and in absence of asynergy. American Journal of Cardiology, 37, 7-11. doi:10.1016/0002-9149(76)90491-4

[9] From, A.M., Scott, C.G. and Chen, H.H. (2010) The development of heart failure in patients with diabetes mellitus and pre-clinical diastolic dysfunction a population-based study. Journal of the American College of Cardiology, 55, 300-305. doi:10.1016/i.jacc.2009.12.003
[10] Poirier, P., Bogaty, P., Phyllippon, F., Garneau, C., Fortin, C. and Dusmesnil, J.G. (2003) Preclinical diabetic cardiomyopathy: relation of left ventricular diastolic dysfunction to cardiac autonomic neuropathy in men with incomplicated well-controlled type 2 diabetes. Metabolism, 52, 1056-1061. doi:10.1016/S0026-0495(03)00091-X

[11] Nagueh, S.F., Middleton, K.J., Kopelen, H.A., Zoghbi, W.A., Quinones, M.A. (1997) Doppler tissue imaging: A noninvasive technique for evaluation of left ventricular relaxation and estimation of filling pressures. Journal of the American College of Cardiology, 30, 1527-1533. doi:10.1016/S0735-1097(97)00344-6

[12] Arques, S., Roux, E. and Luccioni, R. (2007) Current clinical applications of spectral tissue Doppler echocardiography (E/E' ratio) as a noninvasive surrogate for left ventricular diastolic pressures in the diagnosis of heart failure with preserved left ventricular systolic function. Cardiovascular Ultrasound, 5, 16-28. doi:10.1186/1476-7120-5-16

[13] Ommen, S.R., Nishimura, R.A., Appleton, C.P., Miller, F.A., Oh, J.K., Redfield, M.M., et al. (2000) Clinical utility of Doppler echocardiography and tissue Doppler imaging in the estimation of left ventricular filling pressures: A comparative simultaneous Doppler-catheterization study. Circulation, 102, 178-1794. doi:10.1161/01.CIR.102.15.1788

[14] Innelli, P., Sanchez, R., Marra, F., Esposito, R. and Galderisi, M. (2008) The impact of aging on left ventricular longitudinal function in healthy subjets: A pulsed tissue, Doppler study. European Journal of Echocardiography, 9, 241-249.

[15] Galderisi, M. (2006) Diastolic dysfunction and diabetic cardiomyopathy: Evaluation by Doppler echocardiography. Journal of the American College of Cardiology, 48, 1548-1551. doi:10.1016/j.jacc.2006.07.033

[16] Guo, C.Y., Shen, L.H., Li, H.W., Teng, Y.X. and Zhao, S.M. (2009) Relation of hemoglobin A1c to myocardial acoustic densitometry and left ventricular diastolic function in patients with type 2 diabetes mellitus and without evident heart disease. Diabetes Research and Clinical Practice, 83, 365-370. doi:10.1016/j.diabres.2009.01.004

[17] Di Bonito, P., Moio, N., Cavuto, L., Covino, G., Murena, E., Scilla, C., et al. (2005) Early detection of diabetic cardiomyopathy: Usefulness of tissue Doppler imaging. Diabetic Medicine, 22, 1720-1725. doi:10.1111/j.1464-5491.2005.01685.x

[18] Peckova, M., Charvat, J., Schück, O., Zamrazil, V., Bilek, R., Hill, M., et al. (2012) Plasma adrenomedullin and subclinical cardiorenal syndrome in patients with type 2 diabetes mellitus. The Journal of International Medical Research, 40, 1552-1559. doi: $10.1177 / 147323001204000435$ 